finally decided just what the plant is to manufacture. The state supply board "Gossnab", Pravda concludes, must supervise the whole supply process more closely to eliminate such discrepancies.

Far more serious, however, are suggestions raised last week by a group of scientists from Byelorussia that the implementation of radical new technologies is being blocked by interdepartmental wrangles. In a major Pravda article they describe two such cases, in sectors which all planners consider to be of the highest priority - energy and agriculture. The first project, highly thought of by the Institute of High Temperatures of the Soviet Academy of Sciences, would have combined an electrolysis unit with a nuclear power plant so that hydrogen for fuel or industry could be produced during "off-peak" times. This combination of chemistry, electrochemistry and nuclear power engineering ran into the stumbling block of what the group describe as the "excessively rigid specialization of the branches of industry",

The second project, for the production of protein biomass for animal feed using hydrogen-consuming bacteria, was worked out jointly by teams from the Byelorussian and Moldavian academies as long ago as 1976. To be cost effective, however, the byproducts of the synthesis - oxygen, nitrogen and possibly ammonia - would also have been exploited. All these are prime requisites of the mineral fertilizer industry, which itself produces waste gas with a usable hydrogen content. Yet although plans have been drawn up for a pilot biomass plant to be run in conjunction with the "Azot" fertilizer plant in Grodno, neither the Ministry of Chemical Fertilizer Production nor Glavmikrobioprom - the body in charge of microbiological production - can see its way to go ahead.

Vera Rich

\section{European research}

\section{Counting costs}

\section{Brussels}

The knotty problem of putting a value on the European Community's research and development programmes is the subject of new proposals which the European Commission has just put forward. The objective of this soulsearching is to define criteria and methods for both evaluating and exploiting research. The idea stems not from a fit of self-doubt but from the Council of "Research" Ministers in December 1979. There are no hard and fast ideas in the document, but areas of investigation are instead defined. Four pilot projects have been approved, which will give independent experts free rein to put certain programmes under scrutiny. The commission proposes then to use the experience of the experts to formulate a policy for exploiting and evaluating research results. This is to be ready by the end of the year but, before then, the first outlines of the policy will be presented at the International Congress for Research Evaluation in October.

One pilot project has already been completed by six independent experts, who looked into the Community's energy conservation and solar energy activities. Four other expert groups are to investigate programmes of research and development in fusion, radioactive waste management, the "Reference Bureau Programme" concerned with physical standards and critical data, and geothermal energy, the use of hydrogen as a fuel and work on the systems analysis of energy use.

The tightening of the European Community's budgetary belt is one motive for the new initiative, but another is the fear that the results of research are being ineffectively disseminated. The experts will be concentrating on the diffusion of information and in particular how to make the results available to the layman, requiring that more outlets should be found and language barriers overcome. Indeed, one member of the European Parliament has asked in a written question why the Commission does not publish the results of research in English as well as in the author's mother tongue. But the commission says that unless the results of research are first digested, readership is always restricted to specialist circles.

The stickiest part of the process on which the Community has embarked is the evaluation of research whose impact is likely to be long term or even unforeseen. Simplifying the results may help. Thus the report on solar energy and conservation says that the success of the programme cannot be measured in "tonnes of oil saved" and that the use made of research carried out may require further action and will take time. Even so, the chairman of the evaluation team, Ugo Forinelli, is confident that European research in this area is already competitive with that in the United States even though the European budget is much smaller than the American. Forinelli's team has made a number of recommendations about the management of the Community's programme, including the need for more explicit statements of objectives when putting contracts out to tender and some suggestions of areas where research might be concentrated or even discontinued.

The commission seems modestly aware of the inherent limitations of plans to evaluate research. The underlying objective is to strengthen the link between research and development and industrial innovation, and the commission acknowledges that its own research cannot be an important source of commercial inventions. But restrictions on Community expenditure outside the agricultural field are likely increasingly to stimulate the justifying of research. Jasper Becker

\section{Swedish research Lucky science}

\section{Stockholm}

Research is one of the very few areas to be given more money in the budget bill for the fiscal year 1981-82, presented this week in Stockholm. Against the background of a budget deficit amounting to about $\$ 15,000$ million, cutbacks in social services and mounting economic gloom, research received an extra $\$ 28$ million.

Considering that this money is to be divided between the projects of eight ministries, individual increases will not be very great, and in real terms may well be eaten up by inflation, which was 14 per cent in 1980 . One staff member at the Natural Sciences Research Council estimated that the net results of the council's $\$ 2$ million increase will be an unchanged level of activity. But this is better than a cutback, the fate of nearly all other sectors.

The government sees research strengthening Sweden's industrial competitiveness in the long term. The Minister of Industry, Nils Aasling, wants to develop sophisticated chemical and mechanical products, and is to make specific allocations for this purpose in the spring. One sign of this policy is the changing proportions of the space budget being allocated between international and national programmes. In the 1980-81 fiscal year, the Swedish Space Corporation's budget of about $\$ 44$ million was equally divided between international and national activities, but in future the accent will be on national programmes. The corporation's budget has been increased overall to about $\$ 58$ million - a real increase in spite of inflation - about half of this will be used to build the country's first space satellite, Viking, which is to be launched from the European rocket Ariane in May 1984. It is hoped to produce the Viking at half the cost of comparable satellites from other European countries, and the project is planned to give Sweden a profitable national space industry. Another project being planned is an experimental telecommunications satellite.

The lion's share of the increase in research expenditure - about $\$ 16$ million - is to be disbursed by the Education Minister, Jan-Erik Wickstroem, who wants to increase research capacity across the board. He is proposing an increase of about 12 per cent for mathematics and natural science faculties, an average of about 9 per cent for the four research councils as well as 90 new PhD places to be spread over all subjects, $\$ 2$ million for particularly expensive equipment, \$2 million to subsidize lecturers who want to take time off for research and $\$ 1$ million for research libraries. Fifteen new chairs will be set up, among them molecular genetics (Karolinska Institute), medicine (Uppsala) and astrophysics (Gothenburg).

Wendy Barnaby 